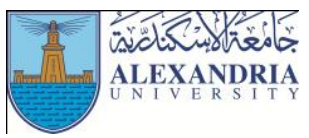

\title{
The Impact of Rehabilitative Exercise Program Accompanied by Massage on Foot Plantar Fasciitis in Some Athletes
}

\section{Hisham Gomaa El-Kersawy ${ }^{1}$}

${ }^{1}$ Lecturer, Department of Biological Sciences and Sports Health , Faculty of Physical Education, alMenoufia University, Egypt

\begin{abstract}
:
This study aimed to investigate the effect of exercise program accompanied by a massage on the plantar fasciitis foot in some athletes, the variables was the muscle force on the arch of the foot and ankle joint, long motor to brace the foot and ankle, foot balance and the ankle joint, improve the degree of pain. The researcher used the experimental approach to design one group with tribal measure, measure dimensions, select sample was purposively strength (10) of the injured athletes and inflammation of the plantar fascia, ranging in age from 15 to 20 years. The most important results: 1. Exercise program accompanied by massage positively affects the plantar fasciitis foot in some athletes on the muscles working force on the arch of the foot and ankle in the movements (Extension, Flexion, Inversion, Eversion), the long motor to brace the foot and ankle joint in modes (Extension, Flexion, Inversion, Eversion), the balance of the foot and ankle joint, improve the degree of pain. 2. great benefit massages are considered in the speed of the rehabilitation of injured plantar fasciitis. 3. Access component of muscle strength and motor-term balance in the arch and ankle injured to normal or close to it in the proper foot after the program ends. 4-Pain level improvement.
\end{abstract}

Keywords: Rehabilitation program exercises - plantar fasciitis - massage.

\section{Introduction and Problem:}

$\mathrm{C}$ oncern about player's health and protecting them against injury is a very important aspect to be performed by professionals in the field of sports. Players are exposed to various injuries either during training or competition, which lead to depriving the player from practicing in sporting activity and decreasing his performance as well as the high functional efficiency necessary for the player, resulting in a bad mental state. These negative effects may extend as a result of the involvement of those injured in training prior to full recovery, leading to a recurrence of injury and almost doubled, so the player needs a longer period of rehabilitation to return to participate in competition in the same functional efficiency which he had prior to the injury.

It is a common injury in athletes, especially those who practice running a lot. Because of continuous and constant stress and fatigue on tissues, the American Family Medicine Association estimates the number of people infected thereof to be more than one million and plantar fascia infection rate in athletes to be 5.4 : $10 \%$ with a spreading rate of $2.5: 5.17 \%$, and 60 : $70 \%$ of injuries associated with running are a result of errors in training, such as excessive increase in the distances traveled by an athlete or a sudden change in training intensity, so it is possible to avoid a lot of injuries through proper performance and exercise of running. (25)

Mariotto (2009) \& Metzner (2010) Refers that ankle joint in a human's life is the main axis in daily movements in general, and sports activities in particular. It is also the base upon which the human body is based and provides him with movement, where it bears $97 \%$ of the body weight, During various sports activities Balance and stability of the ankle joint rely primarily on the superb design of ankle joint bones as well as ligaments, tendons and muscles working there on . $(11: 66-72)(12: 790-$ 796)

Yalçin (2012) Defined plantar fasciitis or inflammation of the plantar ligament, or what is sometimes called the inflammation of fascial tissue (fascial ligament) as "an inflammation in the ligament that protects foot sole". It is a fibrous tissue extending from the bottom surface of the foot at the heel till toes (connects between the heel and foot base), It has a sensitive function where it supports the foot arch as well as distributing body weight on the foot while walking. (21:12) 
Danilo (2015) Refers that plantar fasciitis results from overloading or a sudden collision of the heel bone, it also results from long standing, walking or running on a solid and irregular objects such as stones, resulting in acute inflammation of the lining membrane or heel bone ligament. Overweight and obesity are also factors that contribute to the occurrence of severe heel pains and commonly appear in humans in mid age or in adults who are overweight. (7: 113)

Cheung (2015) Explains that sudden overweight such as pregnancy in women, sudden increase in walking or practicing sports activities may be contributing factors to the incidence of plantar fasciitis. This is in addition to biomechanical disorders (abnormal walking), various types of joint disorders such as rheumatoid, heavy weight lifting, shortage or flexibility weakness of leg rear muscles, excessive flatness of foot (flat foot) or weakness of natural foot arch fixing structure. (5: 140)

Kamonseki (2014) Refers that plantar fasciitis is a result of the use of non-comfortable and high heels shoes that do not contain a pillar for foot arch or a heel pillow. Some studies have indicated that $85 \%$ of foot pains are a result of the bad use of shoes or uncomfortable ones, i.e. harsh and heel wide shoes for people whose work requires standing or walking for long periods and distances.(10:25)

Chong (2007) Explains that symptoms appearing on a person as a result of plantar fascia inflammation are a persistent pain from which the patient suffers most of the time as well as bouts of acute pain in heel center or at its margins. The pain goes worse when the person wakes up in the morning and gets out of bed, or after resting and sitting for period of time then walking and so the pain gradually fades away. It may be improved during the day then come back again. It is more common among women and may last for six months along with treatment, it may also be transformed into a chronic condition which is difficult to treat.(6:56)

Valtonen (2010) Confirms that physical rehabilitation is useful in plantar fasciitis inflammation treatment, depending on the use of certain means so as to increase strength \& flexibility, restore mobility and assist the sufferers to return to the level of activity on which they were prior to the injury. Comfort is a necessary requirement for inflammation treatment. Massage for the bottom of the foot suffering from plantar fascia inflammation assists in the discharge of waste resulting from exerted effort, which helps to feel comfort and to accelerate reducing inflammation.(19: 234)

Aboelella Abdel-Fattah(2000) \&Mohammad Bakry (2001) Kalyani (2004) Confirms the importance of massage for healing plantar fasciitis inflammation, It works to alert and raise muscle tissue, which has a far-reaching effect in improving the contraction of muscle fibers, helping to absorb leaches in tissues and joints helping to reduce pain and get rid of adhesions between soft tissue layers, increase the speed of venous blood flow and accelerates of the lymph session with a positive effect on muscle tone. It also helps to rapidly get rid of stressful \& pain-causing chemicals and wastes of metabolic reactions, in addition to getting rid of nervous tension, muscle pain and contraction, which leads to reducing the tension incident on muscle tendon reducing inflammation in the arch area and thus accelerating pain fade away. (1:27) (13:20) (9: 74)

The researcher noted through his work in sports clubs, the spread of plantar fasciitis injury between players of various sports activities. This led the researcher to build an exercise program using massage to overcome symptoms of such injury and then to reach the full recovery there from.

\section{Research Objective:}

This research aims to identify the impact of an exercise rehabilitation program using massage on foot plantar fasciitis inflammation among some athletes in respect of the following variables:

1-Strength of muscles working on the foot arch and ankle joint movements while (Extension, Flexion, Inversion, Eversion).

2-The dynamic range of foot arch and ankle joint in while (Extension, Flexion, Inversion, Eversion).

3-The balance of foot and ankle joint.

4- Pain level improvement.

\section{Research Hypothesis :}

The exercise rehabilitation program using massage influences foot plantar fasciitis inflammation among some athletes in respect of the following variables:

1- Strength of muscles working on the foot arch and ankle joint movements while (Extension, Flexion, Inversion, Eversion).

2- The dynamic range of foot arch and ankle joint while (Extension, Flexion, Inversion, Eversion).

3- The balance of foot and ankle joint.

4- Pain level improvement. 


\section{Research Importance:}

This is the first scientific study on the rehabilitation of plantar fasciitis injury for some athletes through the design of an exercise rehabilitation program using massage and assessing its impact on the injured athletes, so that they could return to the field and practice specialist sporting activity again in the same physical \& physiological condition on which they were before the injury and also to reduce the size of material and moral losses born by clubs as a result of their players subjection to such injury and the denial of participation in sports activities.

\section{Research Procedure:}

Research Methodology: the researcher used the experimental methodology with the design of one group and both pre and post-measurements.

Research sample: a sample of (10) athletes suffering from plantar fasciitis was chosen intentionally, which ranges from 15 to 20 years old.

\section{- Research Dimensions:}

Human field: This study was conducted on a sample of athletes suffering from plantar fasciitis.

Geographical area: Tanta Sports Stadium.

Temporal range: program was implemented in the time period from $01 / 03 / 2015$ to $30 / 04 / 2015$.

\section{- Means \& Tools of Data Collection:}

References, scientific research and the World Wide Web.

\section{- Research Measurements:}

Height measurement: using Restameter.

Weighting: using medical scale.

Measuring strength of muscles working on foot arch \& ankle: using Tensiometer.

Measuring the range of muscles working on foot arch \& ankle: using Goniometer.

Measuring balance: the test of standing on foot instep using vibration panel (balance).

Measuring pain level: using symmetry visual scale.

\section{- Statistical Analysis:}

The researcher used SPSS software to perform the following statistical calculations:

1- The average, median, standard deviation, splaying and torsion.

2- Analysis of variance.

3- Least significant differences LSD.

4- Change percentage.

Results:

Table (1)

Research sample description $(\mathrm{n}=10)$

\begin{tabular}{|c|c|c|c|c|}
\hline Variables & Mean & Standard deviation & Median & Torsion modulus \\
\hline Age & 23.7 & 2.16 & 23.5 & 0.483 \\
\hline Length & 178 & 5.93 & 179.5 & -1.065 \\
\hline Weight & 68.5 & 8.21 & 65 & 1.148 \\
\hline
\end{tabular}

Table (1) shows that torsion modulus ranges between $( \pm 3)$ which is an evident to sample moderation. 
Table (2)

Indication of pre and post-measures for Non Injured foot and that

suffering from plantar fasciitis for muscle strength variable $(\mathrm{n}=10)$

\begin{tabular}{|c|c|c|c|c|c|c|c|}
\hline \multirow{2}{*}{ Measure } & \multirow{2}{*}{ Variables } & \multicolumn{2}{|c|}{ Non Injured foot } & \multicolumn{2}{|c|}{ Injured foot } & \multirow{2}{*}{ Aver different } & \multirow{2}{*}{ t value } \\
\hline & & M & $\pm \mathrm{Z}$ & $\mathrm{M}$ & $\pm \mathrm{Z}$ & & \\
\hline \multirow{4}{*}{ Pre-measure } & Extension & 18.6 & 1.9 & 10.80 & 1.27 & 8.81 & $13.09 *$ \\
\hline & Flexion & 22.33 & 1.37 & 11.97 & 1.62 & 11.32 & $20.37 *$ \\
\hline & Inversion & 11.75 & 1.52 & 8.35 & 0.59 & 3.43 & $21.40^{*}$ \\
\hline & Eversion & 11.99 & 0.95 & 9.85 & 0.56 & 2.12 & $20.30^{*}$ \\
\hline \multirow{4}{*}{ Post-measure } & Extension & 19.55 & 1.80 & 18.2 & 1.35 & 0.32 & 0.435 \\
\hline & Flexion & 24.52 & 1.46 & 22.8 & 1.31 & 0.27 & 0.432 \\
\hline & Inversion & 12.77 & 1.09 & 14.6 & 1.17 & 0.17 & 0.355 \\
\hline & Eversion & 12.87 & 1.23 & 11.65 & 1.04 & 0.22 & 0.457 \\
\hline
\end{tabular}

Table value of $(\mathrm{T})$ at level of significance $(0.05)(18)=2.1$

* Significant at level of significance (0.05).

Table (3)

Percentage of pre and post-measures for Non Injured foot

and that suffering from plantar fasciitis for muscle strength variable $(\mathrm{n}=10)$

\begin{tabular}{|c|c|c|c|c|}
\hline \multirow{2}{*}{ Measure } & \multirow{2}{*}{ Variables } & \multicolumn{2}{|c|}{ Muscular strength } & \multirow{2}{*}{ Percentage (\%) } \\
\cline { 2 - 5 } & & Non Injured foot & Injured foot & 51.05 \\
\hline \multirow{3}{*}{ Pre-measure } & Extension & 18.62 & 10.80 & 42.05 \\
\cline { 2 - 5 } & Flexion & 22.33 & 11.97 & 33.11 \\
\cline { 2 - 5 } & Inversion & 11.75 & 8.35 & 1.35 \\
\cline { 2 - 5 } & Eversion & 11.99 & 9.85 & 98.49 \\
\hline \multirow{3}{*}{ Post-measure } & Extension & 19.55 & 18.2 & 60.35 \\
\cline { 2 - 5 } & Flexion & 24.52 & 22.8 & 97.78 \\
\cline { 2 - 5 } & Inversion & 12.77 & 14.6 & 95.2 \\
\cline { 2 - 5 } & Eversion & 12.87 & & \multicolumn{2}{|c}{9} \\
\hline
\end{tabular}

Table (4)

Indication of differences between pre and post-measures for Non Injured foot and that suffering from plantar fasciitis for dynamic range variable $(n=10)$

\begin{tabular}{|c|c|c|c|c|c|c|c|}
\hline \multirow{2}{*}{ Measure } & \multirow{2}{*}{ Variables } & \multicolumn{2}{|c|}{ Non Injured foot } & \multicolumn{2}{|c|}{ Injured foot } & \multirow{2}{*}{ Aver different } & \multirow{2}{*}{$\mathrm{T}$ value } \\
\hline & & $M$ & $\pm \mathrm{Z}$ & M & $\pm Z$ & & \\
\hline \multirow{4}{*}{ Pre-measure } & Extension & 12.5 & 2.50 & 6.6 & 1.033 & 6.30 & $9.685^{*}$ \\
\hline & Flexion & 44.3 & 3.86 & 25.8 & 3.368 & 19.6 & $10.864 *$ \\
\hline & Inversion & 41.1 & 4.78 & 20.5 & 6.569 & 21.7 & $8.019 *$ \\
\hline & Eversion & 17.9 & 3.95 & 6.90 & 2.319 & 11.6 & $7.792 *$ \\
\hline \multirow{4}{*}{ Post-measure } & Extension & 14.8 & 2.45 & 14.4 & 1.715 & 0.4 & 0.105 \\
\hline & Flexion & 45.2 & 4.18 & 44.1 & 4.158 & 1.1 & 0.536 \\
\hline & Inversion & 43.5 & 4.76 & 44.8 & 4.408 & 1.3 & 0.341 \\
\hline & Eversion & 19.4 & 3.02 & 19.9 & 3.062 & 0.5 & 0.808 \\
\hline
\end{tabular}

Table value of $(\mathrm{T})$ at level of significance $(0.05)(18)=2.1$

* Significant at level of significance (0.05). 
Table (5)

Percentage of pre and post-measures for Non Injured foot and that suffering from plantar fasciitis for dynamic range variable $(\mathrm{n}=10)$

\begin{tabular}{|c|c|c|c|c|}
\hline \multirow{2}{*}{ Measure } & \multirow{2}{*}{ Variables } & \multicolumn{2}{|c|}{ Muscular strength } & \multirow{2}{*}{ Percentage (\%) } \\
\cline { 2 - 5 } & & Non Injured foot & Injured foot & 37.5 \\
\hline \multirow{3}{*}{ Pre-measure } & Extension & 6.6 & 12.5 & 61.4 \\
\cline { 2 - 5 } & Flexion & 25.8 & 44.3 & 58.7 \\
\cline { 2 - 5 } & Inversion & 20.5 & 41.1 & 37.4 \\
\cline { 2 - 5 } & Eversion & 6.90 & 17.9 & 99.36 \\
\hline \multirow{3}{*}{ Post-measure } & Extension & 14.4 & 14.8 & 97.96 \\
\cline { 2 - 5 } & Flexion & 44.1 & 45.2 & 99.43 \\
\cline { 2 - 5 } & Inversion & 44.8 & 19.4 & 97.88 \\
\cline { 2 - 5 } & Eversion & 19.9 & & 2 \\
\hline
\end{tabular}

Table (6)

Indication of differences between pre and post-measures for Non Injured

foot and that suffering from plantar fasciitis for dynamic range variable

\begin{tabular}{|c|c|c|c|c|c|c|c|}
\hline \multirow{2}{*}{\multicolumn{2}{|c|}{ Variables }} & \multicolumn{2}{|c|}{ Non Injured foot } & \multicolumn{2}{|c|}{ Injured foot } & \multirow{3}{*}{$\begin{array}{c}\text { Aver different } \\
3.43\end{array}$} & \multirow{3}{*}{$\begin{array}{l}\text { T value } \\
5.053^{*}\end{array}$} \\
\hline & & M & $\pm \mathrm{Z}$ & M & $\pm \mathrm{Z}$ & & \\
\hline \multirow{2}{*}{ Test of standing on instep } & Pre-measure & 6.45 & 3.18 & 3.65 & 0.69 & & \\
\hline & Post-measure & 9.49 & 3.76 & 9.17 & 2.68 & 0.36 & 0.278 \\
\hline
\end{tabular}

Table value of $(\mathrm{T})$ at level of significance $(0.05)(18)=2.1$

* Significant at level of significance (0.05).

Table (7)

Percentage of pre and post-measures for Non Injured foot and that suffering from plantar fasciitis for balance variable

\begin{tabular}{|c|c|c|c|c|}
\hline \multirow{2}{*}{ Variables } & & \multicolumn{2}{|c|}{ Muscular strength } & \multirow{2}{*}{ Percentage (\%) } \\
\hline & & Non Injured foot & Injured foot & \\
\hline \multirow{2}{*}{ Test of standing on instep } & Pre-measure & 3.65 & 6.45 & 38.24 \\
\hline & Post-measure & 9.17 & 9.49 & 97.15 \\
\hline
\end{tabular}

Table (8)

Indication of differences between pre and post-measures for Non Injured foot and that suffering from plantar fasciitis for pain level variable $(\mathrm{n}=10)$

\begin{tabular}{|c|c|c|c|c|c|}
\hline \multirow{2}{*}{\multicolumn{2}{|c|}{ Variables }} & \multicolumn{2}{|c|}{ Injured foot } & \multirow{2}{*}{ Aver different } & \multirow{2}{*}{$\mathrm{T}$ value } \\
\hline & & M & $\pm \mathrm{Z}$ & & \\
\hline \multirow{2}{*}{ Pain level } & Pre-measure & 4.55 & 0.69 & 3.43 & $5.053 *$ \\
\hline & Post-measure & 9.19 & 2.68 & 0.36 & 0.278 \\
\hline
\end{tabular}

Table value of $(\mathrm{T})$ at level of significance $(0.05)(18)=2.1$

* Significant at level of significance (0.05).

Table (9)

Percentage of differences between pre and post-measures for Non Injured foot and that suffering from plantar fasciitis for pain level variable $(\mathrm{n}=10)$

\begin{tabular}{|c|c|c|c|}
\hline \multicolumn{2}{|c|}{ Variables } & Injured foot & Percentage (\%) \\
\hline \multirow{2}{*}{ Pain level } & Pre-measure & 3.65 & 38.24 \\
\cline { 2 - 4 } & Post-measure & 9.17 & 97.15 \\
\hline
\end{tabular}


Table (10)

Percentage of differences between pre and post-measures for Non Injured foot and that suffering from plantar fasciitis for muscular strength, pain level variable, balance and pain level $(\mathrm{n}=10)$

\begin{tabular}{|c|c|c|c|}
\hline \multirow{2}{*}{\multicolumn{2}{|c|}{ Variables }} & \multicolumn{2}{c|}{ Percentage $\%$ Post-measure } \\
\cline { 2 - 4 } & & Pre-measure & 98.49 \\
\cline { 2 - 4 } Muscular strength & Extension & 51.05 & 60.35 \\
\cline { 2 - 4 } & Flexion & 42.05 & 97.78 \\
\cline { 2 - 4 } & Inversion & 33.11 & 95.2 \\
\cline { 2 - 4 } & Eversion & 1.35 & 99.36 \\
\hline \multirow{3}{*}{ Dynamic Range } & Extension & 37.5 & 97.96 \\
\cline { 2 - 4 } & Flexion & 61.4 & 99.43 \\
\cline { 2 - 4 } & Inversion & 58.7 & 97.88 \\
\hline Balance & Eversion & 37.4 & 97.15 \\
\hline Pain level & Standing on instep & 38.24 & 96.15 \\
\hline
\end{tabular}

\section{Discussion of Results:}

Tables2,3 \&10 show that there are statistically indicating differences between Non Injured foot and that suffering from plantar fasciitis in muscular strength variables for the Non Injured foot in pre-measurement. Whereas there aren't statistically indicating differences in post-measure between Non Injured and injured foot in muscular strength variables.

Researchers According this improvement in muscular strength variables goes back to the qualifying program in addition to massages, where the program included various and graded-intensity exercises and researcher used different devices and tools according to the physical condition of the injured, which have had a positive impact on the development of the strength of muscles working on foot.

Mukhtar Salem (2000) Clini (2004) \& Ayman Kamal (2007) confirms that the qualifying program is one of the most important points in the way of the return of the injured athlete, the earlier and the Non Injured foot is the start, the more rapidly is the chance of recovery and return to the pitch. (15:130) $(9: 25)(3: 96)$

Mariotto (2009) Refers that the Rehabilitation sporting programs undergo gradual stages such as comfort and protection stage so as to reduce the contractions associated with the injury, the beginning of dynamic range increasing negatively and physically, stage of exercise by gradual resistance when dynamic range reaches $75 \%$ and the power is $50 \%$ of the basic level and finally reaching for lengthening, functional strengthening, polymetric activities and finally the return to the competition. (11: 114)
Danilo (2015) also confirmed that the containment of qualifying program on different exercises for the development of muscular strength of foot arch and ankle and getting it practiced in a gradually regular scientific manner leading to various changes in muscles, such as muscle cross-section increasing, fast fiber size increasing, increasing the size and strength of tendons and ligaments and also increasing the density of capillaries. (7: 225)

Tables 4,5 \&10 show that there are statistically indicating differences between Non Injured foot and that suffering from plantar fasciitis in dynamic range variables for the Non Injured foot in pre-measurement. Whereas there aren't statistically indicating differences in post-measure between Non Injured and injured foot in dynamic range variables of foot arch and ankle.

Researcher According these statistical differences and percentages are a result of injured foot dynamic range being affected as a result of the presence of inflammations in fascial ligament and its persistence for long periods without treatment, leading to the emergence of blood clusters and adhesions inside the heel. Also, negative dynamic range exercises with the help of healers in addition to positive dynamic range exercises have a great importance in getting rid of tumor and pain, the reduction of losses in connective tissue flexibility and restoring the dynamic range and foot $\&$ ankle strength.

Mohammad Ismat (2006) states that the containment of the qualifying program on exercises of stretching and flexibility for joints in addition to the positive impact of the development of muscular strength increase the dynamic range of the joint, where there is a direct correlation between the increase of dynamic range of joint 
and the increase of strength of muscle groups performing dynamic range movements. (14: 77)

Nizi (2015) Explains the importance of flexibility exercises which works on the development muscle prolongation element and increasing flexible properties of muscles and ligaments together, which leads to increased dynamic range of ankle. $(16: 23)$

Metzner (2010) Refers that plantar fascia leads to the occurrence of damages in ligaments, pains, infiltrates and blood spills leading to a decrease in dynamic range as a result of blood clots and the increase of adhesions in the arch and ankle. (12: 690)

Tables $6,7 \& 10$ show that there are statistically indicating differences between Non Injured foot and that suffering from plantar fasciitis in balance variables for the Non Injured foot in pre-measurement. Whereas there aren't statistically indicating differences in post-measure between Non Injured and injured foot in the variable of the balance between foot and ankle.

Researcher According to these statistical differences are a result of that injury leads to automatic sensory reception weakness as a result of an imbalance in the efficiency of sensory receptors located in the portfolio of ligaments and tendons of muscle passing with foot arch; in addition to that pain and fear lead to a weakness in foot balance variable. The more improvement in percentage of injured foot than the Non Injured one in balance variable goes back to the qualifying program in addition to massages.

Researcher Also accounts this change to the improvement of muscular strength of muscles surrounding the joint and increasing the dynamic range of the joint in all directions. This is consistent with what was stated by Wang (2006) \& Mariotto (2009) where they said that balance exercises are one of the most important exercises used in self-reception training for the lower part in general, whereas those exercises are performed through standing on the vibrating panel by both foot and then on one foot while eyes are open and then closed. In addition, training of selfreceiving system is an important aspect that prevents the recurrence of infection. (20: 223) (11: 112)

Steven (2012) Refers that self-receiving of an athlete body is restored through performing balance exercises on vibration panel in different directions from stability. Qualifying program stages may include gradual-load \& intensity exercises which play a great role in balance development. (18: 223)

Confirms that muscular strength exercises don't lead to an improvement in muscle power element only, but also lead to improved balance element, where it works on selfreceiving development for the arch and ankle in various movements of the joint, which leads to the rapid onset of improvement among athletes with plantar fascia inflammation. (8: 126)

Tables $8,9 \& 10$ show that there are statistically indicating differences between pre and post-measurements for the foot suffering from plantar fasciitis in pain level variable for the post-measurement.

This is in line with what was indicated by Osman AlKasaby (2013) in that massage works to stimulate hormones that exist in the form of non-active compounds to turn into an effective substance, also leads to the increased excretion of Adrenaline and gives positive results through the formation of histamine which helps to expand blood vessels. It also helps to improve the harmony between the cerebral cortex and various organs of the body. This is reflected in the strengthening and renewal of tissue and removal of atrophy, and thus massage plays an important role in the rehabilitation of the injury being accompanied with qualification exercises. (17: 64)

This is consistent with what was confirmed by both the American Foundation for Pain (2006) and Ahmed Saleh (2009) in that exercise is a common method in rehabilitation programs to get rid of the pain. It not only keeps health, but also helps to mitigate the pain all time. Physical activities help control pain in the joints and its swelling as a result of articular inflammation. (25) (2: 93)

Valtonin (2010) Explains that massage directly affects the nervous system leading to relaxation and mitigation of pain and tension of muscle tissue, which becomes adherent and debilitating. Massage helps to increase joints' dynamic range by easing muscle tension there around, increasing the activity of the circulatory system, which helps to get rid of toxic outputs that lead to fatigue and pain, activating the natural release of synovial fluid. It also helps to reduce the pain associated with initial injury as massage liberates the secretion of nicotine, which leads to feeling comfortable and relaxed. (19: 123)

\section{Conclusions:}

In the light of research objectives, hypothesis and results, and in the limit of available sample, tools and methods used, the researcher managed to conclude the following:

1- The existence of statistically indicating differences between Non Injured foot and that suffering from plantar fasciitis in muscular strength, dynamic range, balance time and pain level variables on foot arch and ankle for the Non 
Injured foot in pre-measurement. Whereas it is obvious that there aren't statistically indicating differences in postmeasure between Non Injured and injured foot in the same variables.

2- Massages are of great benefit in the rehabilitation of plantar fasciitis.

3- Making muscle strength, dynamic range and balance in the arch and ankle of the injured foot reach the normal rate or close to it in the Non Injured foot after the program ends.

\section{Recommendations:}

In the light of research objectives, its results and the discussion thereof, the researcher recommends the following:

1- Performing further studies and researches on the rehabilitation of plantar fasciitis among athletes, ordinary people and different ages.

2- Allocating a time space within training modules for balance exercises performed from ground standing position, on two-way vibration panel or multi-trend panel as it is useful in players' preparation programs as well as rehabilitation programs of various injuries, especially repeated and chronic injuries.

3- Paying attention to the selection of gear and tools for players in a scientific considering the anatomical conditions of a player's body as of its effective impact in maintaining player's right style and thus protects players from a lot of dangers and injuries.

\section{References:}

1- Abo El-Ela Abdel-Fattah \& Moammed Sobhi Hassanien(2000): "Encyclopedia of Alternative Medicine", Al-Kitab Publishing Center, Cairo.

2- Ahmed Helmy Saleh(2009): "Rehabilitative exercise program and its impact in the carpal tunnel syndrome without surgery," Master thesis, Faculty of Physical Education, Tanta University.

3- Ayman Kamal Kamel(2007): "The impact of using different methods for flexibility special exercise within and outside water on performance and numerical achievement for an emerging swimmer", $\mathrm{PhD}$ thesis, Faculty of Physical Education for Boys, Mansoura University,.

4- Celik D (2014): Joint Mobilization and Stretching Exercise vs Steroid Injection in the Treatment of Plantar
Fasciitis:A Randomized Controlled Study. http://www.ncbi.nlm.nih. gov/pubmed/26400901.

5- Cheung RT (2015) : Intrinsic foot muscle volume in experienced runners with and without chronic plantar fasciitis.J Sci Med Sport. pii: S1440-2440(15)00225-X. doi: 10.1016/j.jsams.2015.11.004.

6- Chong FC. (2007): The electrophysiological and functional effect of shock wave on peripheral nerves. Conf Proc IEEE Eng Med Biol Soc, 2007: 2369-2372.

7- Danilo H (2015): Effect of stretching with and without muscle strengthening exercises for the foot and hip in patients with plantar fasciitis: A randomized controlled single-blind clinical trial Oct 30 . pii: S1356689X(15)00196-4. doi: 10.1016/j.math.2015.10.006.

8- Jean M. (2014) : Ankle Sprain and Instability ,www.allaboutmydoc.com,Article.

9- Kalyani Premkumar (2004): the massage connection anatomy and physiology, Lippincott Williams \& Wilkins, Curr Med Chem, 16 ( 19): 2366.

10- Kamonseki DH (2013): Effect of stretching with and without muscle strengthening exercises for the foot and hip in patients with plantar fasciitis: A randomized controlled single-blind clinical trial. pubmed/26400901.

11- Mariotto S, (2009): Extracorporeal shock wave therapy in inflammatory diseases: Molecular mechanism that triggers anti-inflammatory action. Curr Med Chem, 16 (19): 2366-2372.

12- Metzner G, (2010): High-energy Extracorporeal Shock-Wave Therapy (ESWT) for the treatment of chronic plantar fasciitis. Foot Ankle Int, 31 ( 9): 790-796.

13- Mohammed Bakry(2001): "Traditional and Eastern massages in the alternative medicine", Cairo.

14- Mohammed Esmat(2006) :"The impact of rehabilitation exercising program on frequent sprain of ankle brutal strap in some athletes" Master thesis, Faculty of Physical Education in Tanta.

15- Mukhtar Salem(2000): "Sport injuries", Al-Mering Publication House, Cairo.

16- Niazi NS, (2015) : Effect of the silicone heel pad on plantar fasciitis. J Pak Med Assoc. Nov;65(11 Suppl 3):S123-7.

17- Osman Al-Kasaby(2013): "Foot plantar fasciitis, symptoms, dangers and treatment. 
18- Steven J. (2012) : "Acute Ankle Sprains,Keys to Diagnosis and Return to Play." ,The Physician and Sports medicine, - Vol 30 - No. 12 -

19- Valtonen A, (2010) : Effects of aquatic resistance training on mobility limitation and lower-limb impairments after knee replacement .

20- Wang CJ, (2006): Long-term Results of Extracorporeal Shockwave Treatment for Plantar Fasciitis. Am J Sports Med, 34 ( 4): 592-596.

21- Yalçin E, (2012): Effects of extracorporeal shock wave therapy on symptomatic heel spurs: a correlation between clinical outcome and radiologic changes. Rheumatol Int, 32 ( 2): 343-347.
22- http://www.heelspurs.com/

23- www.painfoundation.org //Treatment Option: A guide for People Living with Pain , American Pain Foundation, 2006 .

24- http://orthoinfo.aaos.org/topic.cfm?topic=a00318 2001

25- American Orthopaedic Foot \& Ankle Society Orthopaedic Foot \& Ankle Foundation. http://www.aofas.org/Pages/Home.aspx.

26- Hotta T : http://www.ncbi.nlm.nih.gov16342847 . Department of Physical Therapy, Human Health Sciences, Graduate School of Medicine,Kyoto University. 